\title{
Reaction of ten peach and ten nectarine cultivars to powdery mildew
}

\author{
HOSSEIN KARBALAEI KHIAVI ${ }^{1 凶}$, ADEL PIRAYESH ${ }^{2}$, \\ SEYED YAGHOUB SEYED MASOUMI ${ }^{2}$, HOSSEIN KHABBAZ JOLFAEI ${ }^{3}$ \\ 1.Department of Plant Protection Research, Ardabil Agricultural and \\ Natural Resources Research and Education Center, AREEO, Ardabil, Iran. \\ 2. Department of Horticulture Crops Research, Ardabil Agricultural \\ and Natural Resources Research and Education Center, AREEO, Ardabil, Iran. \\ 3. Department of Plant Diseases Researches, Iranian Research Institute \\ of Plant Protection, Tehran, Iran.
}

Received: 31.03.2021

Accepted: 26.05.2021

Karbalaei Khiavi H, Pirayesh A, Seyed Masoumi SY, Khabbaz Jolfaei H (2021). Reaction of ten peach and ten nectarine cultivars to powdery mildew. Plant Pathology Science 10(1):1-13. Doi: 10.2982/PPS.10.1.1.

\begin{abstract}
Introduction: Powdery mildew caused by Podosphaera pannosa is one of the most important diseases of peaches and nectarines worldwide, including Iran. The aim of this research was to investigate the response of peaches and nectarines under cultivation in Iran to the disease. Materials and Methods: Reaction of ten peach cultivars vs. Robin, Early Red, Red Top, Shasta, Amesdn, Velvet, Anjiri, Paeizeh, Dixi Red, and Sun Crest, and ten nectarine cultivars vs. Independence, Stargold, Sangold, Sanking, Giuta, Shabrang Karaj, Vega, Orion, Jiova and Veinberger were evaluated for disease in natural and artificial infection conditions in two experiments in a randomized complete block design with three replications over two years at the Meshgin Shahr Agricultural and Natural Resources Research Station. Results: Analysis of variance of experimental data showed that there was a significant difference between cultivars of each plant at a probability level of $1 \%$. Peach cultivars Anjiri and Red top were very resistant, Velvet, Shasta and Early red were resistant; Amesdn, Dixi red and Robin were moderately resistant; Sun crest was susceptible and Paeizeh was in very susceptible. Weinberger nectarine cultivars were resistant and Independence, Stargold, Sanking, Giuta, Shabrang Karaj, Vega, Orion and Jiova cultivars were semi-resistant and Sangold was very susceptible to disease. Conclusion: Eighty percent of the studied peach cultivars are very resistant to semi-resistant and $20 \%$ sensitive and very sensitive, $90 \%$ of the studied nectarine cultivars are resistant to semi-resistant and $10 \%$ susceptible to powdery mildew. Findings of this research should be considered in the management of peach and nectarine powdery mildew.
\end{abstract}

Key words: Diease, Resistant, Sensitive, Podosphaera

$\triangle$ Corresponding author: hossein.karbalaei@yahoo.com 
مقاله يزوهشى

\section{واكنش ده رقم هلو و ده رقم شليل به سفيدك :يودرى}

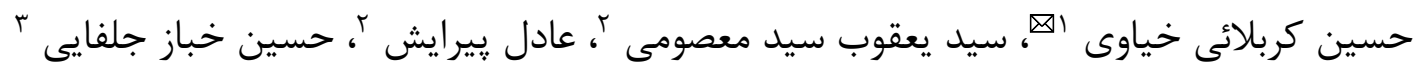

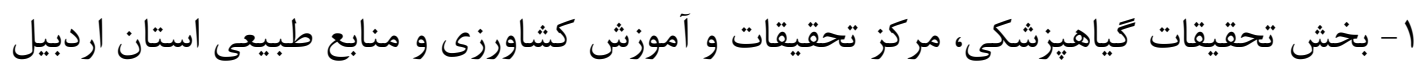

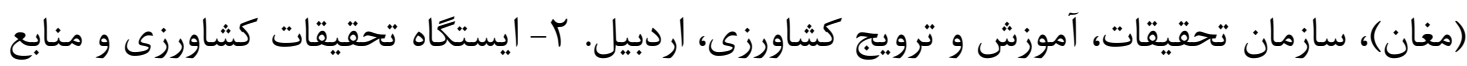

طبيعى مشخين شهر، مركز تحقيقات و آموزش كشاورزى و منابع طبيعى استان اردبيل (مغان)،

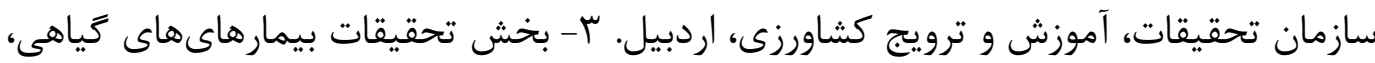
موسسه تحقيقات كياهيزشكى كشور، تهران

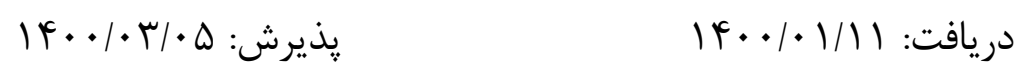

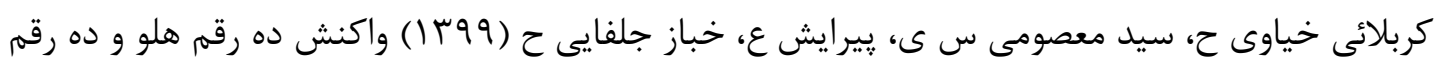

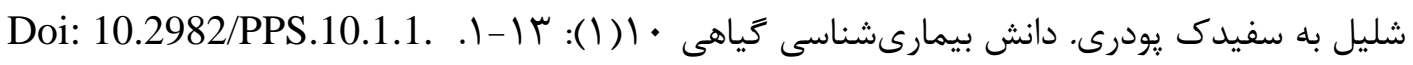

\section{جكيده}

مقدمه: سفيدك يودرى ناشى از Podosphaera pannosa يكى از بيمارىهاى مهرم هلو و شليل در جهان است. هدف از اين يزوهش بررسى واكنش رقمهاى هلو و شليل تحت كشت در ايران دربرابر بيمارى بود. مواد و روشها: واكنش رقمهاى هلوى روبين، ارلىرد، ردتاب، شاستا، آمسدون، ولوت،

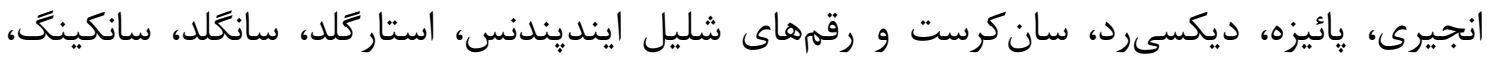

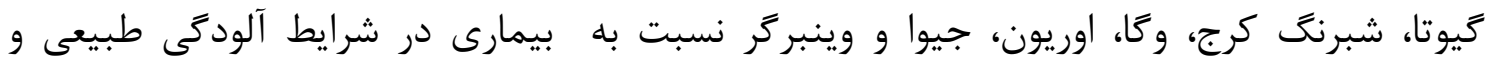

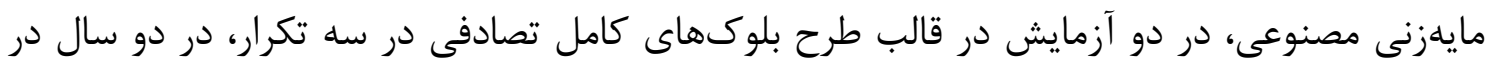

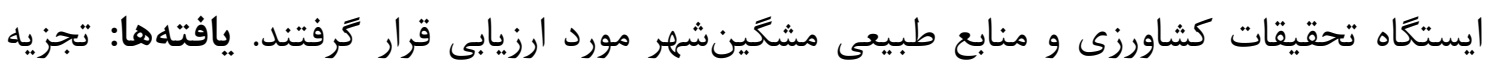
واريانس دادههاى آزمايشها نشان دادند كه بين رقمهاى هر كياه اختلاف معنى دارى در سطح احتمال

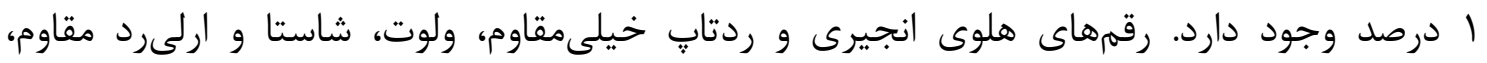

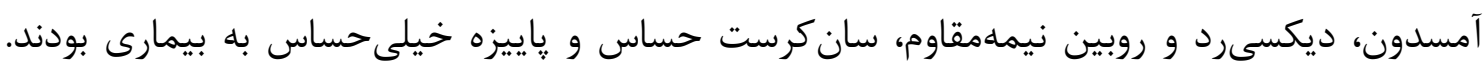

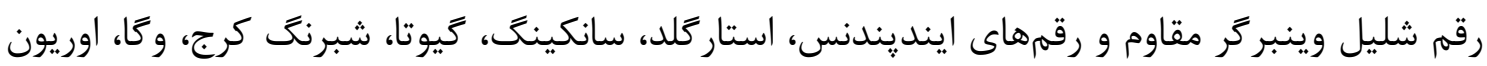

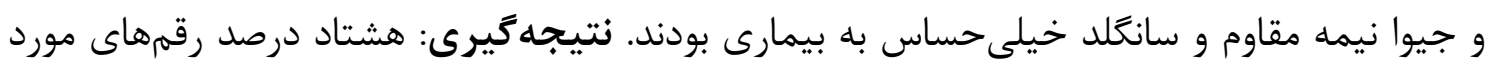

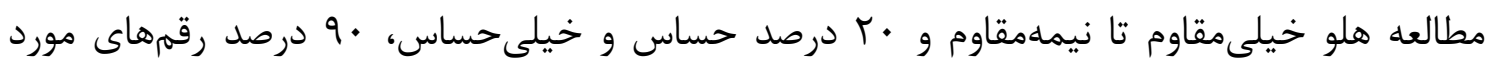
مطالعه شليل مقاوم تا نيمهمقاوم و • ادرصد حساس به بيمارى سفيدى يومى يودرى هستند. يافتههاى اين

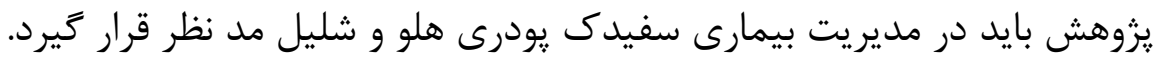

وازَّان كليدى: بيمارى، حساس، مقاوم، Podosphaera

$\triangle$ هسئول مكاتبه: hossein.karbalaei@yahoo.com 


\section{Introduction}

هلو و شليل متعلق به تيره Rosaceae مىباشند. ميوه هلو بزرگ، يوشيده از كرك، گوشتدار و داراى Prunus persica (L.) Batsch var. nucipersica (Suckow) ( هسته شياردار درشت است. شليل نوعى هلوى بدون كرك است. هلو و شليل علاوه بر مصرف تازه خورى در صنايع (C.K. Schneid تبديلى و غذايى از جمله تهيه انواع آب ميوه، مربا، زله و فرآوردههاى مشابه استفاده مىشوند

.(Khbbaz Jolfaee 2017)

بيمارى سفيدك يودرى ناشى از قارج انگل اجبارى Podosphaera pannosa (Wallr.) de Bary يكى از بيمارىهاى مههم هلو و شليل بوده و در اكثر مناطق هلو و شليلكارى دنيا وجود دارد. در صورت فراهم شدن شرايط محيطى مناسب اين بيمارى، بيشتر از هر بيمارى ديگر به درختان هلو و شليل خسارت وارد مى كند و موجب كاهش محصول و كيفيت ميوه و افزايش هزينه توليد مىشود ( Behdad 1990, Ivascu et al. 1996, Fang 1979, Toma and Ivascu 1997, Toma et al. 1998, 2003 رطوبت در مه و شبنم و يا رطوبت بالا بوجود مىآيد (Toma et al. 1998 ). حداكثر جوانهزنى

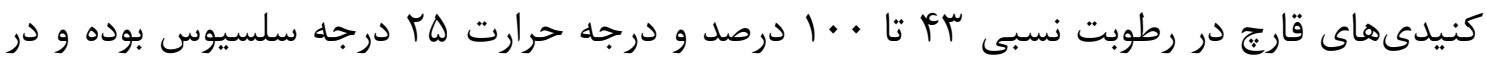
دماى بالاتر از اس درجه سلسيوس رشد قارج كند و در دماى بالاتر از هץ درجه رشد ميسليوم متوقف مى گردد. قارج عامل بيمارى سفيدك يودرى هلو به صورت ميسليوم در شاخههاى آلوده و جوانهاى خفته هلو زمستان كذرانى مى كند(Toma and Ivascu 1997). فيزيولوزيكى مختلف قارج عامل بيمارى سفيدك يودرى هلو را مورد بررسى قرار دادند. جداسازى و شناسايى هشت نزاد قارج، تجزيه و تحليل زنتيكى رقمهاى مختلف در برابر قارج عامل بيمارى بيانگر آن بود كه مقاومت به بيمارى سفيدى يودرى هلو به وسيله يك زن غالب Rpp1 مىباشد. شناسايى و به كارگيرى رقمهاى مقاوم سالمترين شيوه مديريت سفيدكهاى يودرى است، كه طى آن كياه ميزبان به گونهاى تغيير مىيابد كه يا در مقابل آلودگى مقاومت كرده و يا با بروز عكسالعمل كمتر، آلودگى را تحمل مى كند ( Lenne and Wood 1991, Fang 1979, Ahoonmanesh 1999, Pfeiffer 1999, Martin et al. 2001, Toma et al. 2003 يودرى هلو و شليل نيز بسيار حائز اهميت مىباشد. در اين روش به زرميلاسمهاى مقاوم اين درختان ميوه به عنوان קايه در برنامه اصلاح آنها نياز است و اين منابع زنتيكى به صورت نظارت شده نكخدارى

مىشوند ) . Rasoulzadegan 1991, Ivascu et al. 1996, Kervella et al. 1998, Toma et al 1998, Ognjanov et al. 2000, Toma et al. 2003, Ivascu and Buciumanu 2006, Neamtu et 
Ognjanov و همكاران (al. 2008 (2000) در شبه جزيره بالكان با ارزيابى مقاومت رقمهاى مختلف هلو به Podosphaera pannosa مشخص نمودند كه از بين FDV رقم مختلف هلو، زرميلاسمهاى و Kozara ،Uzicka ،Tvidokorka ،Sarunk ،Senabija بيمارى دارند. Neamtu و همكاران (2008) اظهار داشتند كه در برخى از رقمهاى هلو استفاده از قارجكشها جهت مديريت بيمارى سفيدى يودرى بنا به دلايل اقتصادى و زيست محيطى مقرون به صرفه نمىباشد. به همين منظور در شرايط آلودگى طبيعى مقاومت اله رقم مختلف هلو و شليل را در برابر قارج عامل بيمارى مورد ارزيابى قرار دادند. در بررسى آنها رقمهاى Dida و Mihaela مقاوم، رقم

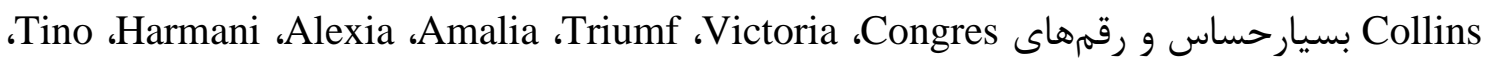
Crimsongold Fantasia Jerseyglo و حساسيت كم و رقمهاى Dixired ،Independence و Cardinal،Antonia Pascal مختلف هلو نسبت به قارج عامل بيمارى سفيدك يودرى انجام دادند. يافتهها نشان داد كه در تلاقى بين پايه مادرى Rubira Pamirskij5 تنها زن غالب مقاومت به بيمارى در كولتيوار Pamirskij5 زن بود. يافتههاى تحقيقى در ويرجينياى آمريكا بيانكر اين مطلب بود كه اين منطقه براى گونههاى مختلف هلو (رقمهاى Red haven، Loring و Red skin) يكى از مراكز مهرم منابع زنتيكى بوده و محققين توصيه نمودهاند كه در برنامههاى اصلاحى از گونههاى بومى وحشى استفاده گردد (Pfeiffer 1999). مقاومت رقمهاى مختلف هلو را در برابر قارج عامل بيمارى مورد ارزيابى قرار دادند. براساس يافته ها حاصله در شرايط آب و هوايى رومانى رقمهاى مورد مطالعه به گروههاى بسيار مقاوم، مقاوم، نيمه مقاوم، حساس و بسيار حساس تقسيمبندى و زرميلاسمهاى Triumf، Congres، و ARK125 Nectared ،Regina ،Morton،Armking،Victoria برابر قارج عامل بيمارى شناخته شدند (Ivascu and Buciumanu 2006, Ivascu and Balan 1994). وجود رقمهاى مختلف هلو و شليل در ايران نيز تنوع گستردهاى را براى اين گونهها فراهم آورده است. در اين مناطق بيمارى سفيدك يودرى هلو از عوامل بسيار مهرم و محدودكننده كشت اين كياهان است. بيمارى سفيدى يودرى هلو در ايران ابتدا در سال عץسا از باغهاى هلوى اطراف تهران گزارش كرديد (Behdad 1990). ساير محققين مختلف در مناطق ميوهخيز كشور نيز وجود قارج عامل بيمارى را ذكر كردهاند (Ahari Babaei and Hoshanghy 1994) (1990) Behdad (19) خسارت بيمارى سفيدك يودرى هلو را در ايران بيش از •له درصد برآورد نموده و اظهار داشت كه اين بيمارى در كليه نواحى هلوكارى ايران وجود داشته و جزء مهمترين بيمارى هلو محسوب مىشود. قارج عامل 
بيمارى مىتواند تمام قسمتهاى سبز درخت هلو را مورد حمله قرار داده و باعث ريزش بركها، كاهش رشد درختان و اختلال در مقاومت گياه به سرما گردد (Behdad 1990). محدوديتهاى مصرف سمهاى شيميايى، شناسايى رقمهاى مقاوم هلو و شليل نسبت به بيمارى را از اهميت ويزهاى برخوردار كرده است. لذا اين بروهش به منظور ارزيابى واكنش ده رقم هلو و ده رقم شليل تحت كشت در مقابل بيمارى سفيدك يودرى در استان اردبيل انجام گرفت.

\section{Materials and Methods}

واكنش • 1 رقم هلو و •1 رقم شليل نسبت به بيمارى سفيدك يودرى در قالب طرح بلوكهاى كامل

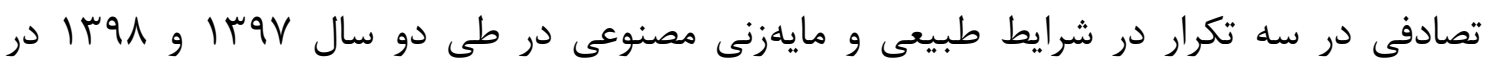
ايستخاه تحقيقات كشاورزى و منابع طبيعى مشخينشهر مورد ارزيابى قرار گرفتند. رقمهاى هلو شامل روبين (Robin)، ارلىرد (Early red)، ردتا» (Red top)، شاستا (Shasta)، آمسدون (Amesdn)، ولوت (Pelvet)، انجيرى (Anjiri)، يائيزه (Paeizeh)، ديكسىرد (Dixi red)، سانكرست (Sun crest) و رقمهاى شليل شامل اينديندنس (Independence)، استاركلد (Stargold)، سانگلد (Sangold)، سانكينگ (Sanking)، كيوتا (Giuta)، شبرنگ كرج (Shabrang karaj)، وگا (Vega)، اوريون (Orion))، جيوا (Viova) و وينبرگر (Veinberger) بودند. رقمهاى مورد مطالعه در طى جند سال كذشته از نقاط مختلف ايران جمعآورى و در كلكسيون ايستخاه تحقيقات كشاورزى و منابع طبيعى مشخينشهر كاشته شده و نكمهارى مىشدند. در طول دوره ارزيابى كليه عمليات باغى به طور يكسان انجام و از هيج آفت كشى استفاده نشد. ارزيابى شدت بيمارى در برگهاى اين رقمها با روشهاى زير انجام گرفت:

ارزيابى واكنش رقمها در شرايط آلودگى طبيعى برگها: ارزيابى آلودگى طبيعى زمانى كه نشانهاى بيمارى سفيدى يودرى كاملاً در روى برىها گسترده بودند در ماههاى خرداد، تير، مرداد و شهريور سالهاى Vqس| و 1وس| انجام گرفت. در اين ارزيابى •له برى از هر رقم (هر رقم جهار درخت) مورد

$$
\text { بررسى قرار گرفت (شكل ()). }
$$

ارزيابى واكنش رقمها با مايهزنى مصنوعى برگها: براى اثبات يافته ها بدست آمده از آلودگى طبيعى، رقمهاى مورد مطالعه به طور مصنوعى در زمان ظهور بيمارى مايهزنى شدند. بدين ترتيب كه كنيدىهاى عامل سفيدى يودرى هلو از برگهاى آلوده پس از شستشو با كلوكز VA/ • درصد در داخل آب سترون شده جمعآورى گرديدند. سيس •ه برى از •ا شاخه جوان هر رقم با غلظت ه • (X كنيدى در هر ميلىليتر محلول كلوكز VN/ • درصد براساس روش Fang (1979) اسيرى شدند. 

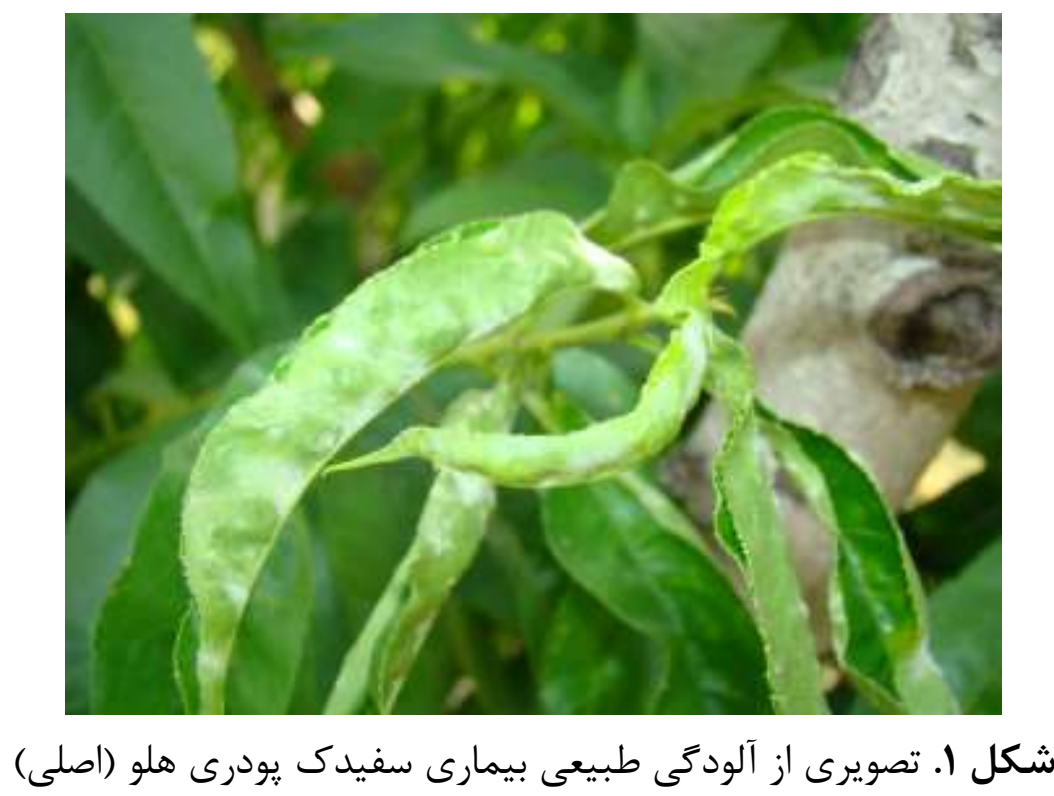

Figure 1. Image of natural infection of peach powdery mildew (Original)

ياشش تا زمانى كه قطرات مايع تازه نمايان شده اما آبدوى Run Off) قطرات بوجود نيامده ادامه يافت. بركَهاى مايهزنى شده بلافاصله با پاكتهاى نازك يوشانده شدند (شكل ؟). شدت بيمارى بعد از آ روز ارزيابى شد ( Ivascu and Buciumanu 2006 ).

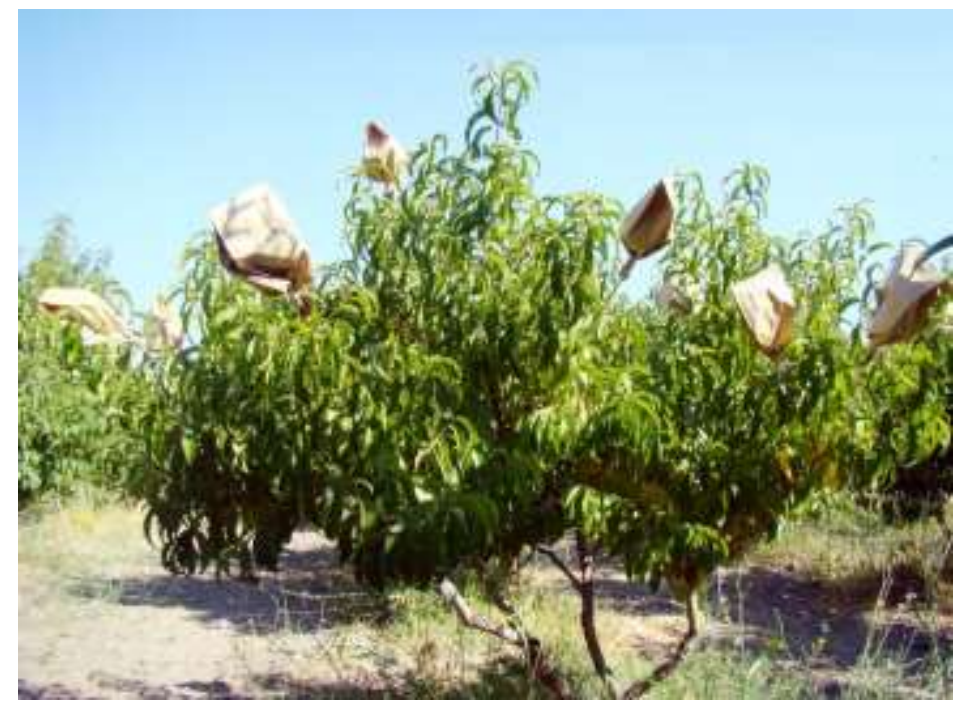

شكل r. يوشاندن برك درختان يس از مايهزنى مصنوعى با عامل بيمارى سفيدك يودرى هلو (اصلى)

Figure 2. Covering tree leaves after artificial inoculation with peach powdery mildew (Original) 
شدت آلودگى در هر دو روش روى بركهاى هلو و شليل براساس درصد يوشش لكهها در كل سطح

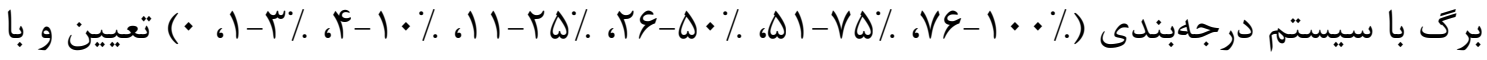
استفاده از اين دادهها شاخص شدت آلودگى Severity Index=SI) براساس اين فرمول:

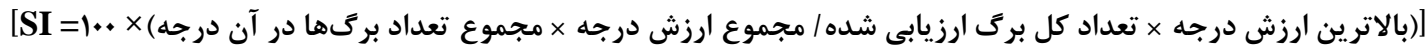

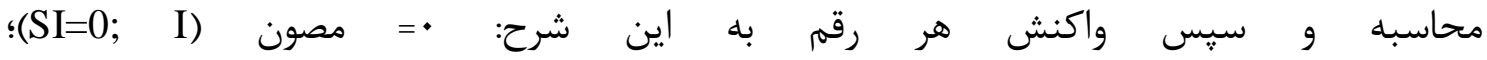

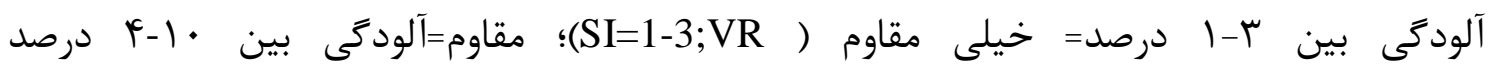

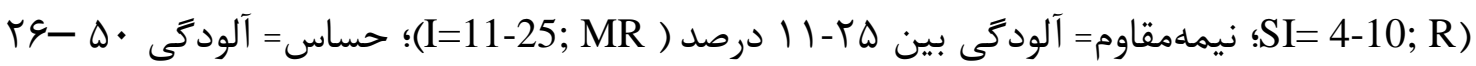

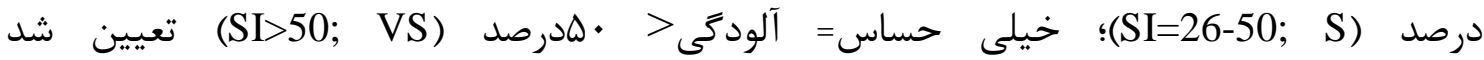
SAS 9.1 (Ivascu and Buciumanu 2006) انجام شد.

\section{Results}

يافتهها

نشانههاى بيمارى سفيدك يودرى در سرشاخهها و جوانهاى برگى هلو و شليل در اوايل فصل رشد مشاهده نشد. توده ريسهاى سفيد رنگ قارج در سطح رويى برگها و اغلب در حاشيه برگهاى شاخههاى جانبى جوان از نيمه دوم خرداد ماه قابل مشاهده بود. مطالعه سير بيشرفت بيمارى طى دو سال نشان داد كه نخستين نشانهاى بيمارى سفيدك يودرى به صورت لكههاى كوجى رنگ يريده روى بركها مشاهده و به تدريج كنيدىهاى قارج روى لكههاى آلوده ظاهر گرديد (ميانخين درجه حرارت • r درجه سلسيوس و ميانگين رطوبت نسبى FV درصد). در طول زمان با مساعد شدن درجه حرارت، تعداد لكهها در روى برگها افزايش و در رقمهاى حساس شدت بيمارى روى برگهاى مسن آلوده به درجه بسيار بالايى رسيد. در نيمه دوم مرداد ماه (ميانگين درجه حرارت رطوبت نسبى FF درصد) شدت بيمارى روى برك هاى رقمهاى حساس و خيلى حساس به بيش از •D درصد و در در اوايل شهريور ماه به · ·1 درصد رسيد. تجزيه واريانس مركب صفت شدت آلودگى برگهاى هلو و شليل در شرايط آلودىى طبيعى و مايهزنى مصنوعى نشان داد بين رقمهاى مورد مطالعه در سطح احتمال 1 درصد اختلاف معنىدارى وجود دارد، ولى بين سالها در دو شرايط آلودكى طبيعى و مايهزنى مصنوعى اختلاف معنى دارى مشاهده نشد (جدول ( ). 


$$
\begin{aligned}
& \text { جدول ا. تجزيه واريانس مركب شدت آلودكى بركهاى هلو و شليل به سفيدك يودرى در شرايط }
\end{aligned}
$$

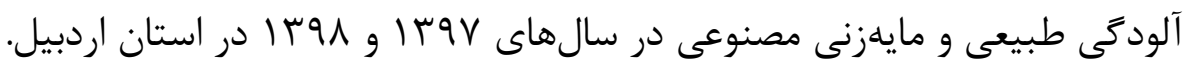

Table 1. Combined analysis of variance for disease severity of different peach and nectarine cultivars to powdery mildew in natural infection and artificial inoculation conditions in 2018 and 2019 in Ardabil province.

\begin{tabular}{|c|c|c|c|c|c|}
\hline \multirow{3}{*}{ Source of variance } & \multirow[b]{3}{*}{$\mathrm{df}$} & \multicolumn{4}{|c|}{ Mean of squares } \\
\hline & & \multicolumn{2}{|c|}{ Peach } & \multicolumn{2}{|c|}{ Nectarine } \\
\hline & & $\begin{array}{l}\text { Natural } \\
\text { Infection }\end{array}$ & $\begin{array}{c}\text { Artificial } \\
\text { Inoculation }\end{array}$ & $\begin{array}{l}\text { Natural } \\
\text { Infection }\end{array}$ & $\begin{array}{l}\text { Artificial } \\
\text { Inoculation }\end{array}$ \\
\hline Year & 1 & $0.014^{\mathrm{ns}}$ & $0.043^{\mathrm{ns}}$ & $0.211^{\mathrm{ns}}$ & $0.003^{\text {ns }}$ \\
\hline Replication & 2 & $0.002^{\text {ns }}$ & $0.010^{\text {ns }}$ & $0.001^{\mathrm{ns}}$ & $0.018^{\mathrm{ns}}$ \\
\hline Year $\times$ Replication & 2 & $0.024^{\mathrm{ns}}$ & $0.002^{\mathrm{ns}}$ & $0.002^{\mathrm{ns}}$ & $0.127^{\mathrm{ns}}$ \\
\hline Cultivar & 9 & $1.504^{* *}$ & $1.256^{* *}$ & $0.134^{* *}$ & $0.161^{* *}$ \\
\hline Year $\times$ Cultivar & 9 & $0.010^{\mathrm{ns}}$ & $0.006^{\mathrm{ns}}$ & $0.004^{\mathrm{ns}}$ & $0.009^{\text {ns }}$ \\
\hline Error & - & 0.017 & 0.012 & 0.035 & 0.032 \\
\hline C.V. & - & 12.18 & 9.96 & 16.45 & 14.72 \\
\hline
\end{tabular}

**: Significant in 1 percent probability, ns: Non significant

$$
\text { مقايسه ميانكين شدت بيمارى در رقمهاى هلو و واكنش آنها در جدول با آورده شده است. }
$$

جدول r. شدت بيمارى سفيدك يودرى و واكنش •ا رقم هلو در شرايط آلودگى طبيعى و مايهزنى

Table 2. Disease severity of powdery mildew on 10 peach cultivars in natural infection

\begin{tabular}{|c|c|c|c|c|c|}
\hline \multirow[t]{2}{*}{ No. } & \multirow[t]{2}{*}{ Genotype } & \multicolumn{2}{|c|}{ Natural Inoculation } & \multicolumn{2}{|c|}{ Artificial Infection } \\
\hline & & $\begin{array}{l}\text { Disease } \\
\text { severity }\end{array}$ & Reaction & $\begin{array}{l}\text { Disease } \\
\text { severity }\end{array}$ & Reaction \\
\hline 1 & Amesdn & $21.00 \mathrm{c}$ & MR & $21.167 \mathrm{c}$ & MR \\
\hline 2 & Sun crest & $35.667 \mathrm{~b}$ & $\mathrm{~S}$ & $36.00 \mathrm{~b}$ & $\mathrm{~S}$ \\
\hline 3 & Paeizeh & $75.833 \mathrm{a}$ & VS & $73.00 \mathrm{a}$ & VS \\
\hline 4 & Velvet & $9.333 \mathrm{~d}$ & $\mathrm{R}$ & $10.833 \mathrm{~d}$ & $\mathrm{R}$ \\
\hline 5 & Shasta & $8.000 \mathrm{~d}$ & $\mathrm{R}$ & $10.00 \mathrm{~d}$ & $\mathrm{R}$ \\
\hline 6 & Early red & $7.8330 \mathrm{~d}$ & $\mathrm{R}$ & $8.833 \mathrm{~d}$ & $\mathrm{R}$ \\
\hline 7 & Dixi red & $20.333 \mathrm{c}$ & MR & $21.667 \mathrm{c}$ & MR \\
\hline 8 & Anjiri & $2.000 \mathrm{e}$ & VR & $2.833 \mathrm{e}$ & VR \\
\hline 9 & Red top & $2.667 \mathrm{e}$ & VR & 2.833 & VR \\
\hline 10 & Robin & $22.167 \mathrm{c}$ & MR & 23.00 & MR \\
\hline \multicolumn{2}{|c|}{ LSD 5\% } & 5.138 & & 4.275 & \\
\hline
\end{tabular}
and artificial inoculation conditions.

$\mathrm{VR}=$ Very resistant, $\mathrm{R}=$ Resistant, $\mathrm{MR}=$ Medium resistant, $\mathrm{S}=$ susceptible, $\mathrm{VS}=$ Very susceptible 
بنابر اين رقمهاى هلوى انجيرى و ردتاب خيلىمقاوم، ولوت، شاستا و ارلىرد مقاوم، آمسدون، ديكسى رد و روبين نيمهمقاوم، سانكرست حساس و ياييزه خيلى حساس به بيمارى هستند.

براى درك بهتر تفاوت واكنش رقمها به بيمارى براساس ميانگين شدت بيمارى در شرايط آلودىى

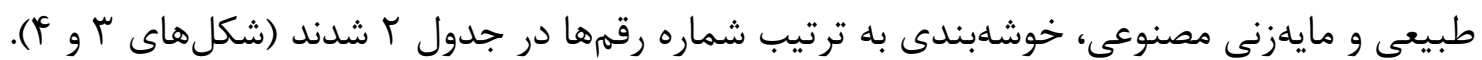

\section{Dendrogram}

Dendrogram using Ward Method

Rescaled Distance Cluster Combine

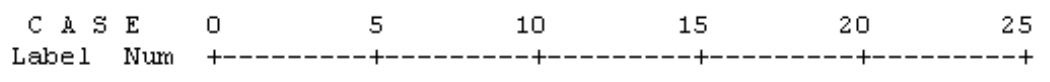

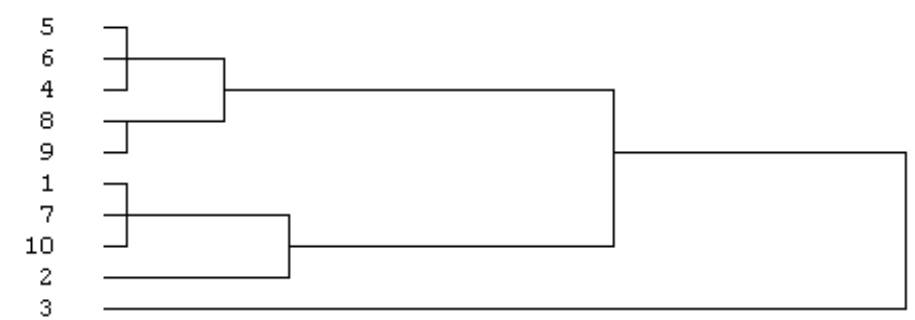

شكل س. خوشابندى • ا رقم هلو براساس شدت بيمارى سفيدك يودرى در شرايط آلودگى طبيعى. Figure 3. Cluster analysis of ten peach cultivars base on disease severity of powdery mildew in natural infection condition.

\section{Dendrogram}

Dendrogram using ward Method

Rescaled Distance Cluster Combine

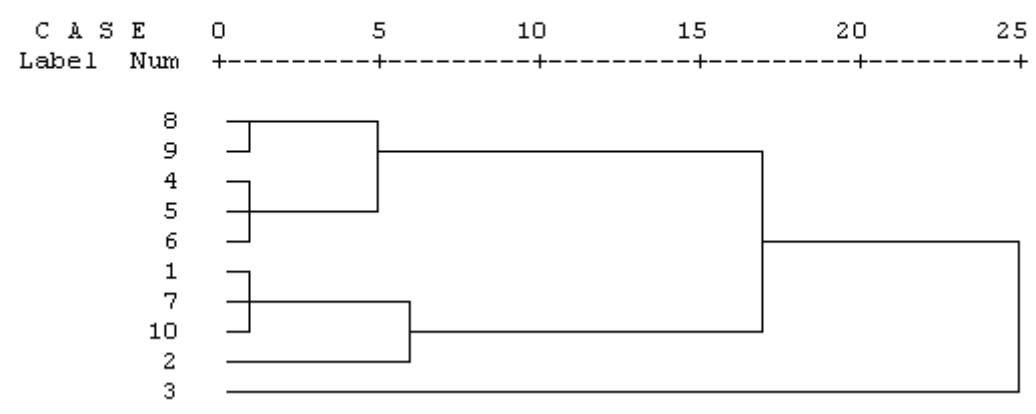

شكل f. خوشهبندى • ا رقم هلو براساس شدت بيمارى سفيدى يودرى در شرايط مايهزنى مصنوعى برگ

Figure 4. Cluster analysis of ten peach cultivars base on disease severity of powdery mildew in artificial inoculation condition. 
رقمهاى شليل نيز از نظر واكنش به بيمارى نسبت به يكديگر در هر دو شرايط آلودگى طبيعى و

مايهزنى مصنوعى تفاوت قابل توجهى داشتند. مقايسه ميانگين با آزمون دانكن در سطح احتمال هـ درصد نشان داد، كه وينبرگر مقاوم، اينديندنس، استارگلد، سانكينگ، گيوتا، شبرنگ كرج، قرمز پاييزه كرج، وگا، اوريون و جيوا نيمهمقاوم و سانگلد حساس به بيمارى سفيدى يودرى هستند (جدول س). جدول س. شدت بيمارى سفيدى يودرى و واكنش • ارقم شليل در شرايط آلودگى طبيعى و مايهزنى

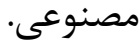

Table 3. Disease severity of powdery mildew on 10 nectarine cultivars in natural infection and artificial inoculation conditions.

\begin{tabular}{cccccc}
\hline \multirow{2}{*}{ No. } & \multirow{2}{*}{ Genotype } & \multicolumn{2}{c}{ Natural Infection } & \multicolumn{2}{c}{ Artificial Inoculation } \\
\cline { 3 - 6 } & & Disease severity & Reaction & Disease severity & Reaction \\
\hline 1 & Independence & $16.67 \mathrm{~b}$ & $\mathrm{MR}$ & $24.17 \mathrm{ab}$ & $\mathrm{MR}$ \\
2 & Stargold & $12.50 \mathrm{bc}$ & $\mathrm{MR}$ & $16.67 \mathrm{bc}$ & $\mathrm{MR}$ \\
3 & Sangold & $26.67 \mathrm{a}$ & $\mathrm{S}$ & $30.0 \mathrm{a}$ & $\mathrm{S}$ \\
4 & Sanking & $12.50 \mathrm{bc}$ & $\mathrm{MR}$ & $14.17 \mathrm{bc}$ & $\mathrm{MR}$ \\
5 & Giuta & $11.67 \mathrm{bc}$ & $\mathrm{MR}$ & $14.17 \mathrm{bc}$ & $\mathrm{MR}$ \\
6 & Shabrang karaj & $11.67 \mathrm{bc}$ & $\mathrm{MR}$ & $16.67 \mathrm{bc}$ & $\mathrm{MR}$ \\
7 & Vega & $17.50 \mathrm{~b}$ & $\mathrm{MR}$ & $21.67 \mathrm{ab}$ & $\mathrm{MR}$ \\
8 & Orion & $19.17 \mathrm{ab}$ & $\mathrm{MR}$ & $20.0 \mathrm{~b}$ & $\mathrm{MR}$ \\
9 & Jiova & $16.67 \mathrm{~b}$ & $\mathrm{MR}$ & $19.17 \mathrm{~b}$ & $\mathrm{MR}$ \\
10 & Veinberger & $7.50 \mathrm{c}$ & $\mathrm{R}$ & $7.50 \mathrm{c}$ & $\mathrm{R}$ \\
\hline & LSD 5\% & 7.744 & & 8.705 & \\
\hline
\end{tabular}

خيلى مقاوم (VR)، مقاوم (R))، نيمه مقاوم (MR)، (MR)، حساس (S) $\mathrm{VR}=$ Very resistant, $\mathrm{R}=$ Resistant, $\mathrm{MR}=$ Medium resistant, $\mathrm{S}=$ susceptible براى درك بهتر تفاوت واكنش رقمها به بيمارى براساس ميانگين شدت بيمارى در شرايط آلودگى طبيعى و مايهزنى مصنوعى، خوشهبندى به ترتيب شماره رقمها در جدول ب شدند (شكلهاى له و \&).

\section{Dendrogram}

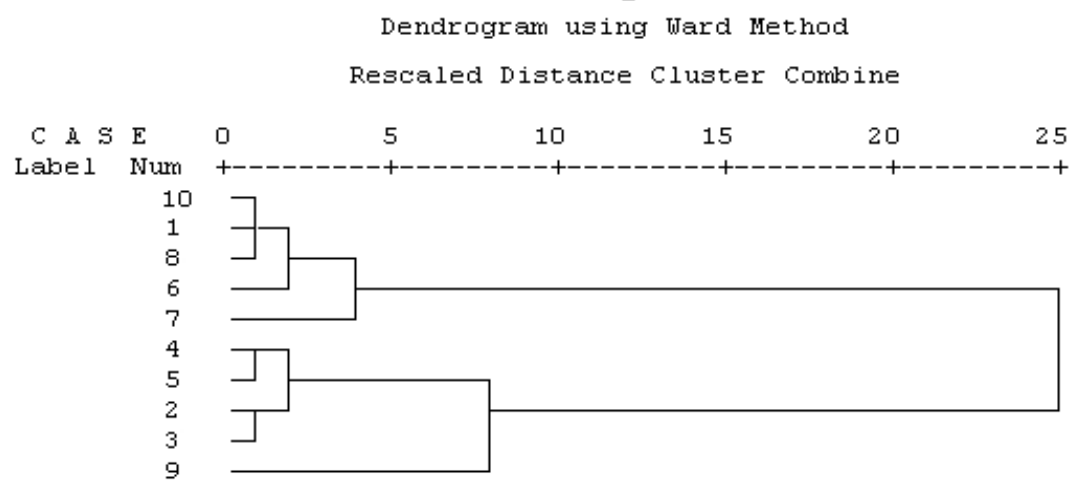

شكل ه. خوشهبندى • ا رقم شليل براساس شدت بيمارى سفيدى يودرى در شرايط آلودىى طبيعى. s. Figure 5. Cluster analysis of ten nectarine cultivars base on disease severity of powdery mildew in natural infection condition. 


\section{Dendrogram}

Dendrogram using Ward Method

Rescaled Distance Cluster Combine

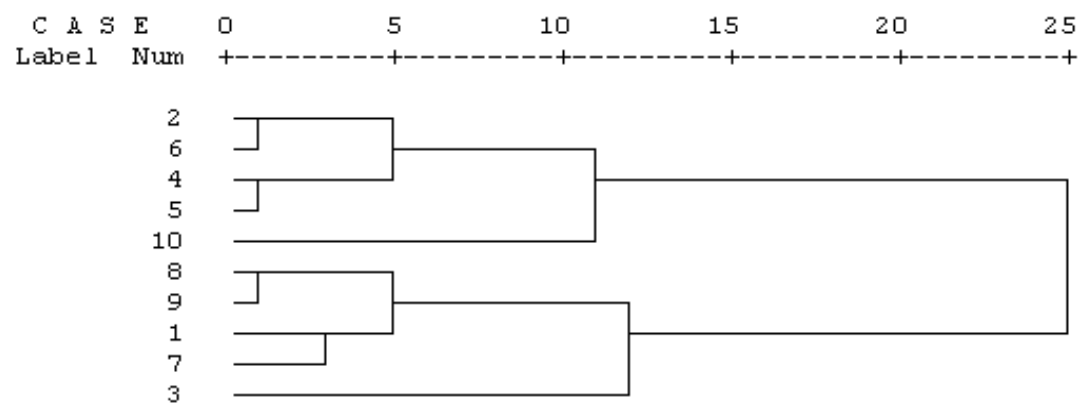

شكل و. خوشهبندى •l رقم شليل براساس شدت بيمارى سفيدى يودرى در شرايط مايهزنى

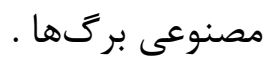

Figure 6. Cluster analysis of ten nectarine cultivars base on disease severity of powdery mildew in artificial inoculation condition.

\section{Discussion}

يافتههاى اين آزمايش در مورد روند بروز علايم بيمارى سفيدى يودرى هلو با يافتههاى بلدست آمده

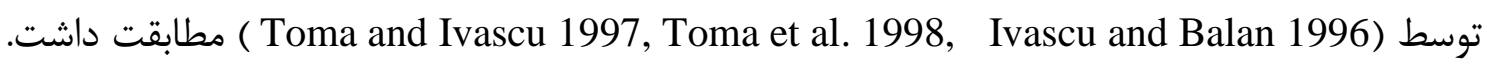
) با انجام (Behdad 1990, Ahari Babaei and Hoshanghy 1994, Toma and Ivascu 1997) تحقيقات مختلفى نشان دادهاند كه قارج عامل بيمارى سفيدى يودرى هلو با مساعد شدن شرايط

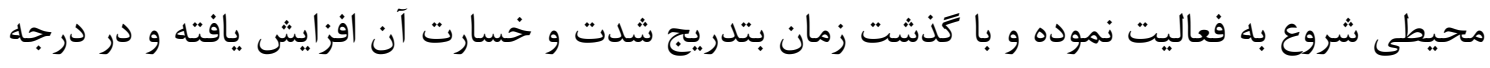
حرارت بالاى هץ درجه سلسيوس رشد و فعاليت قارج عامل بيمارى متوقف شده است. يافتههاى مشابهى در بررسىهاى انجام شده در استان اردبيل بدست آمد. يافتهاى اين يزوهش نيز نشان داد كه رقمهاى مورد بررسى هلو و شليل از نظر واكنش به بيمارى نسبت به يكديكر تفاوت قابل توجهى دارند. به طور كلى از رقمهاى مورد مطالعه هلو ·r درصد خيلى

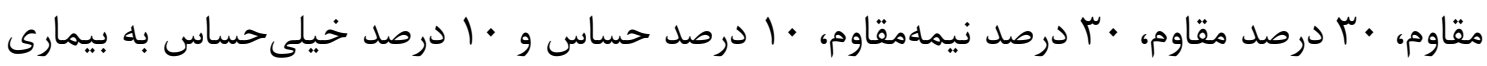
سفيدك يودرى هستند. ده درصد رقمهاى شليل مورد مطالعه مقاوم، •1 درصد نيمهمقاوم، • إدرصد حساس به بيمارى سفيدى يودرى هلو هستند. تحقيقات مشابهى توسط ) Lenne and Wood 1991, Ivascu et al. 1996, Kervella et al. 1998, Toma et al. 2003, Ivascu and Buciumanu 2006, (Neamtu et al. 2008

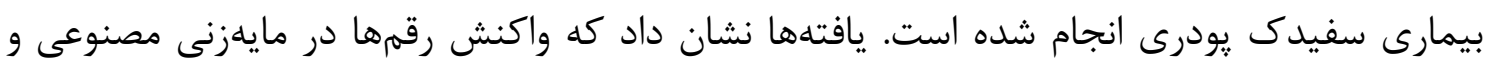


آلودگى طبيعى تا حدود زيادى يكسان است، اين يافتهها اردبيل با يافتههاى محققين در نقاط مختلف

دنيا مطابقت دارد (Neamtu et al. 2008, Ivascu and Buciumanu 2006 ).

\section{Conclusion}

\section{نتيجه}

شناسايى و استفاده از رقمهاى مقاوم بهترين روش مديريت بيمارى سفيدى يودرى هلو و شليل ناشى از Pannosa است. اين يزوهش نشان داد كه هشتاد درصد رقمهاى تحت كشت هلو در ايران

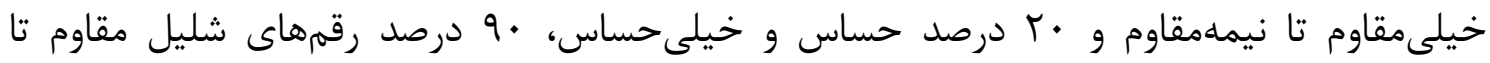

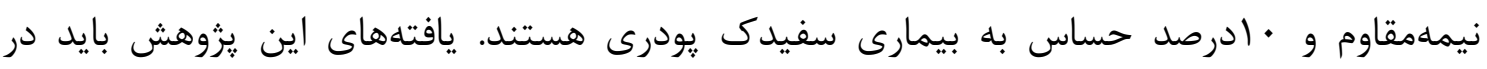
مديريت بيمارىهاى سفيدك يودرى هلو و شليل مد نظر قرار خيرد.

\section{References}

Ahari Babaei A, Hoshanghy AH (1994) Diseases of Fruit Trees and Vines. Uremia University Press, Iran. 186p. (In Persian).

Ahoonmanesh A (1999) Principles of combating plant diseases. Publishing Center, University of Technology. 324p. (In Persian).

Behdad E (1990) Phytopathology and Important Plant Diseases of Iran. Isfahan, Neshat Press. 110p. (In Persian).

Fang Z (1979) Methods in Plant Pathology. Agricultural Press, Beijing P.R., China, $345 \mathrm{p}$.

Ivascu A, Balan V (1994) Behavior of some peach and nectarine cultivars and hybrids at the attack of mildew under the climatic conditions of the southern area of Romania. Proceedings of $24^{\text {th }}$ International Horticultural Congress, Kyoto, Japan, 21-27.

Ivascu A, Balan V, Toma S (1996) Peach and nectarine genitors with highly resistant to powdery mildew. Scientific Sessions ICPP 125-129.

Ivascu A, Buciumanu A (2006) Situation of peach resistance to diseases in Romania. International Journal of Horticultural Science and Technology 12:65-69.

Kervella J, Pascal T, Pfeiffer F, Dirlenwanger E (1998) Breeding for multi resistance in peach trees. Acta Horticulture 465:177-181.

Khbbaz Jolfaee H (2017). Identification and Management of Peach Leaf Curl Disease. Iranian Research Institute of Plant Protection, Tehran, Iran, 35p. (In Persian).

Lenn JM, Wood D (1991) Plant disease and the use of wild germplasm. Annual Review of Phytopathology 29:35-63. 
Linde M, Debener T (2003) Isolation and identification of eight races of powdery mildew of roses (Podosphaera pannosa (Wallr.: Fr.) de Bary and the genetic analysis of the resistance gene Rpp1. Theoretical and Applied Genetics 107:256262.

Martin M, Piola F, Chessel J, Heizmann P (2001) The domestication process of the modern rose, genetic structure and allelic composition of the rose complex. Theoretical and Applied Genetics 102:398-404.

Neamtu M, Barbulescu A, Petcu A, Ilie A, Calinita C, Mocanu S (2008). Evaluation of the genetic resistance of some apricot and peach cultivars confronted with diseases. Scientific Papers of the Research Institute for Fruit Growing Pitesti, Romania 24:41-44.

Ognjanov V, Vujanic-Varga D, Gasic K, Nadj B (2000) Disease resistance in apple, pear and peach germplasm originating from the Balkan Peninsula. In $25^{\text {th }}$ International Horticultural Congress, Part 3: Culture Techniques with Special Emphasis on Environmental Implications, 513:63-68.

Pascal T, Pfeiffer F, Kervella J (2012) Powdery mildew resistance in the peach cultivar Pamirskij5 is genetically linked with the Gr gene for leaf color. Horticultural Science 45:150-152.

Pfeiffer DG (1999) Virginia apple and peach tree survey. Virginia Agricultural Statistics Service, Richmond, Virginia Bulletin 68:11-16.

Rasoulzadegan Y (1991) Temperate Zone Pomology: Physiology and Culture. Isfahan University Press. 759p. (In Persian).

Toma S, Ivascu A (1997) Behavior of some peach and nectarine varieties and hybrids to mainly diseases: leaf curl and powdery mildew in Romania. Proceedings of $25^{\text {th }}$ International Horticultural Science Congress, 9-12 September Lednice na Morave, 174-176.

Toma S, Ivascu A, Oprea M (1998). Highlights of epidemiology of the fungus Sphaerotheca pannosa var. persicae in the southern zone of Romania. In IV International Peach Symposium 465:709-714.

Toma S, Ivascu A, Oprea M, Delian E (2003) Evaluation of powdery mildew resistance at some peach and nectarine cultivars and hybrids by physiological parameters. Acta Horticulture 623:291-298. 